\title{
Un album de photographies fin de siècle, sous la direction de Pierre Wat
}

\section{Michel Arrous}

\section{(2) OpenEdition}

1 Journals

\section{Édition électronique}

URL : http://journals.openedition.org/studifrancesi/568

DOI : 10.4000/studifrancesi.568

ISSN : 2421-5856

Éditeur

Rosenberg \& Sellier

\section{Édition imprimée}

Date de publication : 1 avril 2015

Pagination : 185

ISSN : 0039-2944

\section{Référence électronique}

Michel Arrous, "Un album de photographies fin de siècle, sous la direction de Pierre Wat ", Studi Francesi [En ligne], 175 (LIX | I) | 2015, mis en ligne le 01 avril 2015, consulté le 18 septembre 2020. URL : http:// journals.openedition.org/studifrancesi/568 ; DOI : https://doi.org/10.4000/studifrancesi.568

Ce document a été généré automatiquement le 18 septembre 2020.

\section{(c) (i) (9)}

Studi Francesi è distribuita con Licenza Creative Commons Attribuzione - Non commerciale - Non opere derivate 4.0 Internazionale. 


\title{
Un album de photographies fin de siècle, sous la direction de Pierre Wat
}

\author{
Michel Arrous
}

\section{RÉFÉRENCE}

Aa. Vv., Un album de photographies fin de siècle. Sous la direction de Pierre WAT, avec les contributions de Cédric Lesec et Jérôme DELATOUR, Grenoble, INHA-ELLUG-MSH AlpesUniversité Stendhal, 2013, pp. 212.

1 Dans sa présentation intitulée «La domestication de l'artiste» (pp. 9-20), Pierre WAT analyse le changement radical qui s'est produit, entre 1820 et 1890, dans le regard porté sur l'artiste et son environnement, à travers une série de portraits de peintres et de sculpteurs représentés dans des poses étudiées et selon un poncif immuable. Depuis Le Chef d'œuvre inconnu, nombreuses sont les études et les œuvres consacrées à ce topos, qu'on pense aux articles parus dans L'Artiste et la Revue illustrée, ou aux toiles de FantinLatour et de Courbet. Avec les vues d'ateliers attribuées à Edmond Bérard, on est dans le stéréotype d'une monstration organisée par les artistes eux-mêmes, avec le concours du photographe qui procède à une véritable mise en scène de l'atelier, lieu mythique. Il ne s'agit pas d'un reportage mais d'«une sorte de reconstitution figée» dans laquelle l'artiste mime une convention afin de mieux ressembler à ce qu'attend son client. Ces clichés de l'atelier devenu un lieu mondain, voire un showroom saturé d'objets (bibelots, antiquités, souvenirs d'Orient qui souvent l'emportent sur les abattis) rappellent inévitablement celui de Coriolis dans Manette Salomon (1867). Avec la complicité d'un photographe spécialisé dans ce genre de portrait, ces artistes académiques - il n'y a parmi eux aucun impressionniste - se mettent en scène dans un dispositif muséal, véritable décor où tout est apprêté pour la prise de vue. Et même quand il lui arrive, rarement, de s'absenter du portrait, l'artiste a pris soin d'«arranger» la scène! Le peintre ou le sculpteur s'est transformé en décorateur peu soucieux de la 
vraisemblance - on note d'ailleurs l'omniprésence d'un ameublement cossu -, pour ne pas dire en étalagiste, selon une pratique d'époque illustrée par les Goncourt dans leur maison d'Auteuil (La Maison d'un artiste, 1881). On est à mille lieues de l'image de l'artiste d'avant-garde. Cet «Art de l'arrangement» (expression d'un journaliste en 1885) transforme l'atelier, même quand son caractère privé est souligné, en un lieu de représentation et de réception à des fins commerciales: celui de Dantan jeune est une galerie-magasin. P. Wat conclut très justement: «On croyait avoir affaire à la vie, ça n'en était que le spectacle». Qu'il s'agisse de notabilités (Bouguereau, Falguière, Rosa Bonheur, Landelle, Dubuffe) ou d'artistes privés de commandes officielles mais n'ayant jamais fait partie des Refusés, tous adhèrent au faux-semblant, la plupart rejouent le geste de la création dans un décor à l'usage du bourgeois, «dupe consentante, et pourtant jamais rassasiée». Ces images confirment l'étude fondatrice de Philippe Junod, «L'atelier comme autobiographie» (Künstlerbilder - Images de l'artiste, 1998). 